\title{
PREVALENCE OF KERATOCONUS IN PATIENT COMING FOR LASIK FOR CORRECTION OF MYOPIA OR MYOPIC ASTIGMATISM
}

\author{
By
Mahmoud Mohamed Ismail, Abd Al-Ghany Ibrahim Abd Al-Ghany and Mohamed Sabry Mohamed

Departments of Ophthalmology, Faculty of Medicine, Al-Azhar University

Corresponding author: Mohamed Sabry Mohamed

E-mail: drmsm788@gmail.com, Mobile: 01067790999

\begin{abstract}
Background: Keratoconus (KC) is a corneal collagen disorder in which the central portion of the cornea becomes thinner and bulges forward in a cone-shaped fashion resulting in myopia, irregular astigmatism, and eventually visual impairment.

Objective: Use of Pentacam topography to detect the prevalence of keratoconus and keratoconus suspect in patients coming for LASIK for correction of myopia and myopic astigmatism.

Patients and methods: A retrospective non-randomized clinical study included 1000 eyes of 500 patients coming for LASIK for correction of myopia and myopic astigmatism. All patients had undergone full ophthalmic history, history of ocular surgeries, complete ophthalmic examination (visual acuity, uncorrected visual acuity (UCVA) \& best corrected visual acuity (BCVA), anterior segment examination using Slit-lamp biomicroscopy, intraocular pressure (IOP) measurement by applanation tonometry and fundus examination. In this retrospective clinical study, data from Pentacam (Allegro Oculyzer) such as K readings, corneal thickness, thinnest location and cylinder was retrieved from patient's records coming for LASIK in the period from August 2018 to July 2019 to detect keratoconus and keratoconus suspect.
\end{abstract}

Results: In our study, there was high prevalence of keratoconus. It was $6.6 \%$, which was more than the commonly cited figures of $(0.05-0.23 \%)$ for western countries. Conclusion: This study showed that the prevalence of keratoconus in patients seeking refractive surgery was $6,6 \%$ and the incidence of keratoconus suspect was 2, $6 \%$, this high incidence of keratoconus in these sample groups reflects the high incidence of keratoconus in the general population of Middle East countries compared with the western countries.

Keywords: Keratoconus, Deep anterior lamellar keratoplasty, Laser in situ keratomileusis, Penetrating keratoplasty.

\section{INTRODUCTION}

Keratoconus has been classically described as bilateral asymmetrical progressive ectatic condition of the cornea leading to thinning of the cornea and irregular astigmatism. The etiopathogenesis is still under research and it may be the final manifestation of diverse pathologic processes. With better understanding of the disease and new imaging modalities as well as the advent of refractive surgery, it is being diagnosed much more often and much earlier than in the past (Nikhil, 2013).

The natural history of disease is variable. Typically, at about the age of puberty, the keratoconic process starts and usually. Over a period of next 10-20 
years, the process continues until the progression gradually stops (Naderan et al., 2015). The severity of the disorder at the time the progression stops can range from very mild irregular astigmatism to severe thinning, protrusion, and scarring requiring keratoplasty (Coskunseven et al., 2013).

Despite the major advances in diagnosing and managing keratoconus, the cause of $\mathrm{KC}$ is still not confirmed. Many suggest that it is multifactorial, various genes, proteinases, and environmental factors have been implicated in its etiology. Although classically defined as a predominantly degenerative disease, with mechanically induced trauma accelerating its course, however accumulating evidence suggests a pivotal role for inflammation in the pathophysiology of KC. Several reports have linked various inflammatory mediators (cytokines) with KC (Wisse et al., 2015).

Eye rubbing is strongly linked with keratoconus (Wei et al., 2011). Environmental factors may contribute to the wide variation in prevalence. Geographical locations with plenty of sunshine and hot weather such as India (Kulkarni et al., 2016). In addition, Middle East have higher prevalence than locations with cooler climates and less sunshine such as Finland, Denmark, Minnesota and Japan (Millodot et al., 2015 and Murphy et al., 2015).

\section{PATIENTS AND METHODS}

This study was conducted in Ophthalmology Department, Al Hussein University Hospital, Faculty of Medicine, Al-Azhar University, Nour Al-Haya Center and Royah Center.
This was a retrospective nonrandomized clinical study included 1000 eyes of 500 patients coming for LASIK for correction of myopia and myopic astigmatism.

Time from: August 2018- July 2019.

\section{Inclusion criteria:}

Patients with myopia or myopic astigmatism, age ranging from 18-40 years with clear cornea no previous ocular surgeries.

\section{Exclusion criteria:}

Age less than 18 years or more than 40 years, systemic diseases which contraindicate LASIK, increase intraocular pressure and any corneal scar or degeneration or clinical evidence of keratoconus by Slit Lamp.

In this retrospective clinical study, data from Pentacam (Allegro Oculyzer) such as $\mathrm{K}$ readings, corneal thickness, thinnest location and cylinder was retrieved from patient's records coming for LASIK in the period from August 2018 to July 2018 to detect Keratoconus and Keratoconus suspect.

\section{Statistical analysis:}

Data were qualitatively represented as number, percentage and quantitatively represented by mean \pm SD. Difference and association of qualitative variable was by Chi square test (X2) and differences between quantitative independent multiple was by ANOVA or Kruskal Wallis. P value at $<0.05$ was considered significant. 


\section{PREVALENCE OF KERATOCONUS IN PATIENT COMING FOR LASIK... 527}

\section{RESULTS}

This study included 1000 eyes of 500 patients and the result showed that the prevalence of keratoconus was $6.6 \%$ and suspected $2.6 \%$ and normal $90.8 \%$ (Table 1).

Table (1): Prevalence of keratoconus was $6.6 \%$ and suspected $2.6 \%$ and normal $\mathbf{9 0 . 8 \%}$

\begin{tabular}{|l|c|c|}
\hline \multicolumn{1}{|c|}{ Prevalence } & N & $\%$ \\
\hline Normal & 908 & 90.8 \\
\hline Suspected Keratoconus & 26 & 2.6 \\
\hline Keratoconus & $\mathbf{6 6}$ & $\mathbf{6 . 6}$ \\
\hline Total & $\mathbf{1 0 0 0}$ & $\mathbf{1 0 0 . 0}$ \\
\hline
\end{tabular}

Male were more than half in suspected among normal group with no significant and in keratoconus group while only $39 \%$ difference among groups (Table 2).

Table (2): Gender distribution between different groups

\begin{tabular}{|c|c|c|c|c|c|c|}
\hline \multicolumn{2}{|c|}{ Gender } & Normal & Suspect & Keratoconus & Total & $\mathbf{P}$ \\
\hline \multirow[t]{2}{*}{ Male } & $\mathbf{N}$ & 177 & 7 & 18 & 202 & \multirow[t]{4}{*}{0.12} \\
\hline & $\%$ & $39.0 \%$ & $53.8 \%$ & $54.5 \%$ & $40.4 \%$ & \\
\hline \multirow{2}{*}{ Female } & $\mathbf{N}$ & 277 & 6 & 15 & 298 & \\
\hline & $\%$ & $61.0 \%$ & $46.2 \%$ & $45.5 \%$ & $59.6 \%$ & \\
\hline \multirow[t]{2}{*}{ Total } & $\mathbf{N}$ & 454 & 13 & 33 & 500 & \\
\hline & $\%$ & $100.0 \%$ & $100.0 \%$ & $100.0 \%$ & $100.0 \%$ & \\
\hline
\end{tabular}

Regarding age distribution between studied groups there was no significant difference among groups regard age as normal group age was distributed as $27.4 \pm 4.7$ and suspected $28.15 \pm 1.62$ and keratoconus $28.93 \pm 6.51$ (Table 3).

Regarding K1 distribution among groups there was significant difference among groups regard $\mathrm{K} 1$ as normal group was significantly lower $41.94 \pm 3.15$ and suspected $45.5 \pm 2.54$ and keratoconus 47.92 \pm 4.78 (Table 3). Regarding K2 distribution among groups there was significant difference among groups regard K2 as normal group was significantly lower $44.94 \pm 3.29$ and suspected $48.5 \pm 2.55$ and keratoconus $50.16 \pm 5.23$ (Table 3).

There was significant difference among groups regard $\mathrm{K}$ average as normal group was significantly lower $43.44 \pm 3.16$ and suspected 47.0 \pm 2.58 and Keratoconus 49.04 \pm 4.76 (Table 3).

Regarding thinnest location distribution, there was significant difference among groups regard as normal group was significantly higher $544.09 \pm 64.36$ and suspected $467.42 \pm 24.16$ and keratoconus

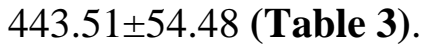


Table (3): Age, K1, K2, K average and thinnest location distribution between studied groups

\begin{tabular}{|c|c|c|c|c|c|}
\hline \multicolumn{2}{|c|}{ Parameters } & Mean \pm Std & Minimum & Maximum & $\mathbf{P}$ \\
\hline \multirow[t]{3}{*}{ Age } & Normal & $27.4053 \pm 4.76036$ & 19.00 & 40.00 & \multirow[t]{3}{*}{0.192} \\
\hline & Suspect & $28.1538 \pm 1.62512$ & 25.00 & 29.00 & \\
\hline & Keratoconus & $28.9394 \pm 6.51412$ & 21.00 & 38.00 & \\
\hline \multirow[t]{3}{*}{ K1 } & Normal & $41.9427 \pm 3.15722$ & 35.00 & 52.00 & \multirow{3}{*}{$\begin{array}{c}\mathbf{0 . 0 0} * \\
*\end{array}$} \\
\hline & Suspect & $45.5000 \pm 2.54951$ & 41.00 & 49.00 & \\
\hline & Keratoconus & $47.9242 \pm 4.78559$ & 38.00 & 56.00 & \\
\hline \multirow[t]{3}{*}{$\mathbf{K} 2$} & Normal & $44.9427 \pm 3.29722$ & 38.00 & 55.00 & \multirow{3}{*}{$\begin{array}{c}\text { 0.00* } \\
*\end{array}$} \\
\hline & Suspect & $48.5000 \pm 2.55987$ & 44.00 & 52.00 & \\
\hline & Keratoconus & $50.1667 \pm 5.23874$ & 41.00 & $\mathbf{5 9 . 0 0}$ & \\
\hline \multirow{3}{*}{$\begin{array}{c}\mathbf{K} \\
\text { average }\end{array}$} & Normal & $43.4427 \pm 3.16722$ & 36.50 & $\mathbf{5 3 . 5 0}$ & \multirow{3}{*}{$\begin{array}{c}\mathbf{0 . 0 0} * \\
*\end{array}$} \\
\hline & Suspect & $47.0000 \pm 2.58951$ & 42.50 & $\mathbf{5 0 . 5 0}$ & \\
\hline & Keratoconus & $49.0455 \pm 4.76827$ & 39.50 & $\mathbf{5 7 . 5 0}$ & \\
\hline \multirow{3}{*}{$\begin{array}{l}\text { Thinnest } \\
\text { location }\end{array}$} & Normal & $544.0914 \pm 64.36224$ & 410.00 & 670.00 & \multirow{3}{*}{$\begin{array}{c}\text { 0.00* } \\
*\end{array}$} \\
\hline & Suspect & $467.4231 \pm 24.16307$ & 411.00 & 490.00 & \\
\hline & Keratoconus & $443.5152 \pm 54.48055$ & 387.00 & 602.00 & \\
\hline
\end{tabular}

There was significant difference among groups regard cylinder as normal group was significantly higher $-1.41 \pm 0.58$ and suspected $-2.86 \pm 0.92$ and keratoconus $3.74 \pm 1.61$ (Table 4).

Table (4): Cylinder distribution among studied groups

\begin{tabular}{|c|c|c|c|c|c|c|}
\hline $\begin{array}{l}\text { Parameters } \\
\text { Cylinder }\end{array}$ & $\begin{array}{c}\text { Mean } \pm \\
\text { Std. } \\
\text { Deviation }\end{array}$ & Median & Minimum & Maximum & $\begin{array}{c}\text { Kruskal } \\
\text { Walis }\end{array}$ & $\mathbf{P}$ \\
\hline Normal & $\begin{array}{c}-1.418 \pm \\
0.585\end{array}$ & -1.35 & -3.60 & -0.66 & \multirow[t]{3}{*}{371.55} & \multirow[t]{3}{*}{$\begin{array}{c}\text { 0.00* } \\
*\end{array}$} \\
\hline Suspect & $\begin{array}{c}-2.868 \pm \\
0.926\end{array}$ & -2.75 & $-4.20-$ & -1.32 & & \\
\hline Keratoconus & $\begin{array}{c}-3.740 \pm \\
1.616\end{array}$ & -3.85 & $-6.20-$ & -1.70 & & \\
\hline
\end{tabular}

\section{DISCUSSION}

The total prevalence of keratoconus entirely differed according to the geographical location. Michel et al. (2011) described that the prevalence was 0.3 per 100.000 in Russia. Kulkarni et al. (2016) stated that it is usually associated with hot climate and low socioeconomic state of the population. In addition, the frequency of attacks of eye allergy with subsequent eye rubbing has a significant role in development of keratoconus. Sedarogullari et al. (2013) made a study on candidates for refractive surgery in Turkey and found a prevalence of $8.1 \%$.

Ethnic differences may account for the differences in the reported prevalence of keratoconus. The reports of two surveys in the UK indicate prevalence 4.4 and 7.5 times greater for Asian (Indian, Pakistani and Bangladeshi) subjects compared with white Caucasians. Hashemi et al. (2013). 


\section{PREVALENCE OF KERATOCONUS IN PATIENT COMING FOR LASIK... 529}

In our study, the prevalence of the disease in patients seeking refractive surgery Prevalence of keratoconus was $6.6 \%$ and suspected $2.6 \%$. This was considered high prevalence.

Concerning age distribution in relation to grade of keratoconus, Aylin et al. (2011) found that the distribution ratios of keratoconic eyes in younger (21 years), middle (21-40 years), and older (>40 years) age groups were $17.2 \%, 75.3 \%$, and $7.5 \%$, respectively.

Bariah et al. (2012) found that the distribution ratios of keratoconic eyes were $71.1 \%$ of males and $28.9 \%$ of females. In our study, there was no significant difference among groups as regard age.

Regarding sex distribution of keratoconus, Aylin et al. (2011) documented that the distribution ratios of those of patients according to their genders were $37.8 \%$ for women and $22 \%$ for men.

In our study, male were more than half in suspected and in Keratoconus group, while only $39 \%$ among normal group with no significant difference among groups.

David et al. (2011) found a strong "expected" relationship between thinner cornea and keratoconus.

In our study, there was a significant difference among groups regard $\mathrm{K}$ average.

\section{CONCLUSION}

Our study showed that the incidence of keratoconus in patients seeking refractive surgery was $6,6 \%$ and the incidence of keratoconus suspect was 2, $6 \%$, this high incidence of keratoconus in these sample groups reflects the high incidence of keratoconus in the general population of Middle East countries compared with the western countries.

\section{REFERENCES}

1. Aylin T, Muftuoglu $H$ and Ertan $M$ (2011): Keratoconus Clinical Findings According to Different Age and Gender Groups. Cornea; 27(10):1109-1113.

2. Bariah M, Mustafa A and Choong $\mathbf{Y}$ (2012): Clinical characteristics of keratoconus patients in Malaysia: a review from a cornea specialist centre. J Ophthalm, 5(1):38-42.

3. Coskunseven E, Sharma D, Jankov M, Kymionis G, Richoz $O$ and Hafezi F. (2013): Collagen copolymer toric phakic intraocular lens for residual myopic astigmatism after intrastromal corneal ring segment implantation and corneal collagen crosslinking in a 3-stage procedure for keratoconus. J Cataract Refract Surg. 39(5):722-9.

4. David M, Yan L, and Maolong T (2011): Keratoconus Diagnosis with Optical Coherence Tomography Pachymetry Mapping. Ophthalmology, 115(12): 21592166.

5. Hashemi H, Mehdi K, and Akbar F (2013): Prevalence and Associations of keratoconus. Ophthalmic Epidemiology, 20(6): 385-391.

6. Kulkarni M, Nangia V, Matin $A$ and Bhojwani K. (2016): Prevalence and associations of keratoconus in rural Maharashtra in central India: The central India Eye Medical Study Am J Ophthalmol. 148:760-5.

7. Michel M, Einat, Sophie A, Esther A, and Ariela G. (2011): Epidemiologic study of keratoconus. Ophthalmic Epidemiology, 18(2): 91-97.

8. Millodot M, Gordon A, Shneor E and Liu $Y$ (2015): The genetic and environmental factors for keratoconus. Biomed Res Int, 795738. 
9. Murphy PJ, Yousuf BI and Quantok AJ (2015): Incidence and severity of keratoconus in Asir province, Saudi Arabia.Br J Ophthalmol, 89:1403-6.

10. Naderan M, Shoar S, Kamaleddin M, Rajabi M, Naderan $M$ and Khodadadi $M$ (2015): Keratoconus Clinical Findings According to Different Classifications. Cornea, 34(9):1005-11.

11. Nikhil S (2013): Epidemiology of keratoconus, Indian $\mathbf{J}$ of Ophthalmol, 382,383 .

12. Serdarogullari $H$, Mehmet $\mathbf{T}$ and Hatice K. (2013): Prevalence of Keratoconus and
Subclinical Keratoconus in Subjects with Astigmatism Using Pentacam Derived Parameters. J Ophthalmic Vis Res, 8(3): 213219.

13. Wei RH, Khor W, Lim $L$ and Tan DT (2011): Contact lens characteristics and contrast sensitivity of patients with keratoconus. Eye Contact Lens, 37(5):30711.

14. Wisse R, Kuiper, Gans R, Imhof $S$, Radstake T and Van A. (2015): Cytokine Expression in Keratoconus and its Corneal Microenvironment: A Systematic Review. Ocul Surf, 13(4):272-83. 
معدل إنتشار القرنية المخروطية في المرضى القادمين لعمل

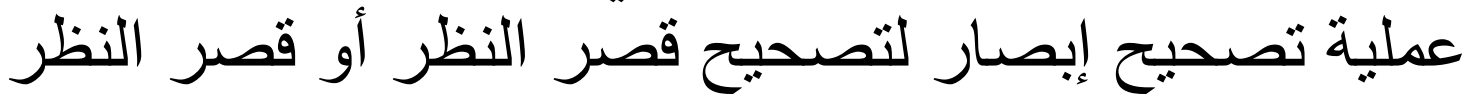

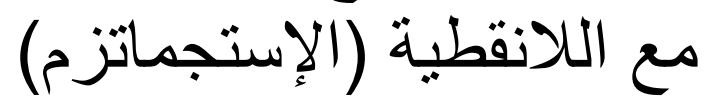

محمود محمد اسماعيل، عبد الغني إبراهيم عبد الغني، محمد صبري محمد إسماعيل قسم طب وجراحة العيون، كلية الطب، جامعة الأزهر

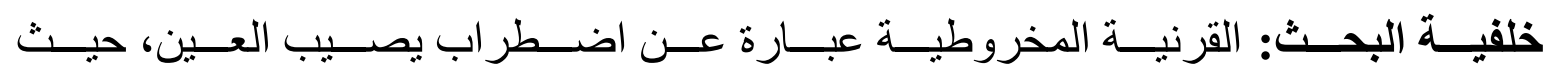

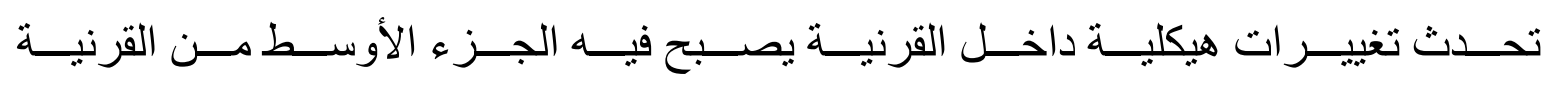

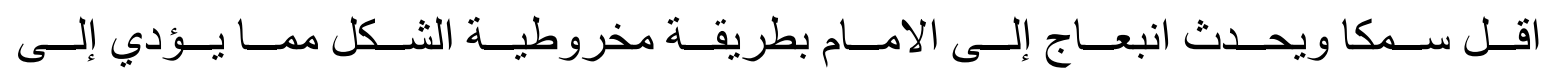

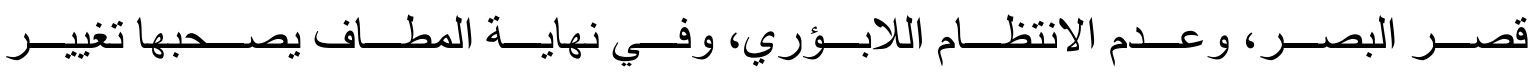

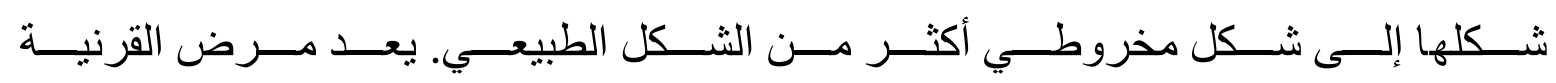

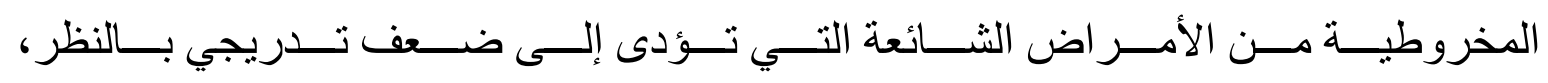

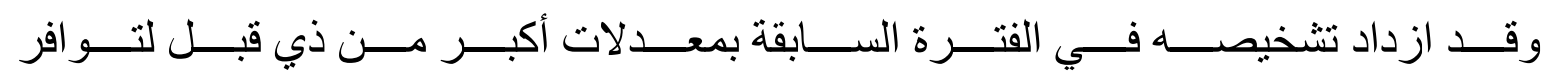

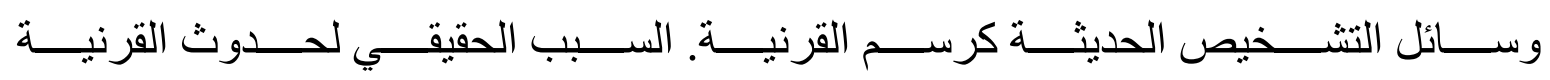

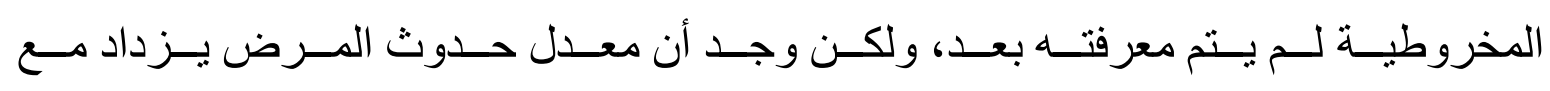

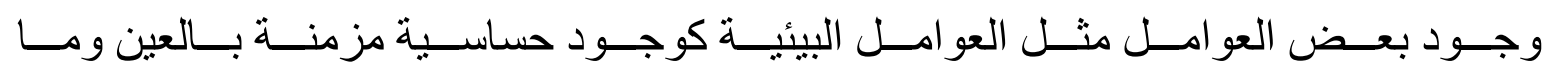

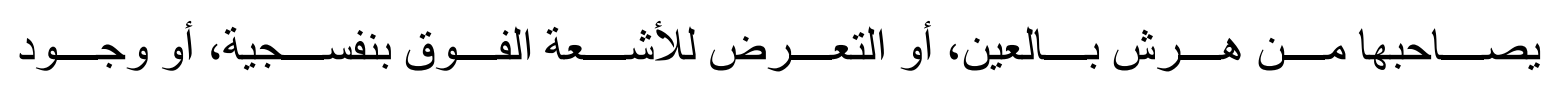
تاريخ مرضى في العائلة للقرنية المخروطية.

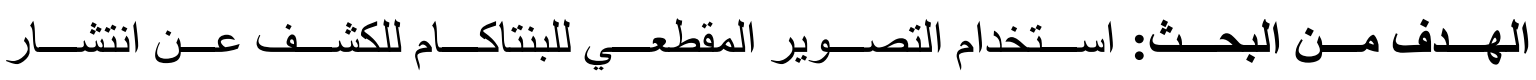

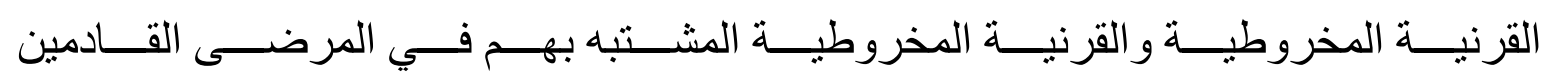
لليزك لتصحيح قصر النظر والإستجماتزم قصر النظر.

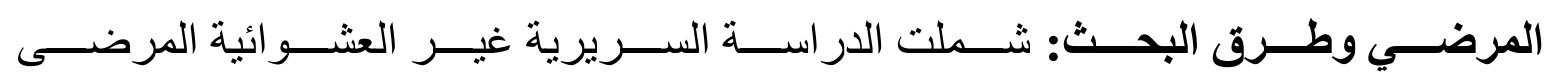

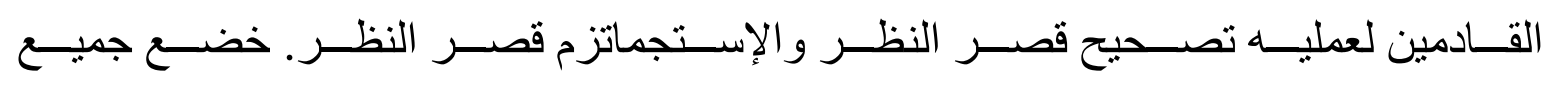

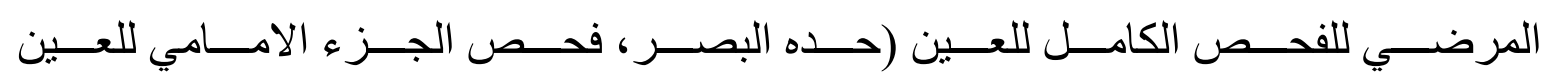

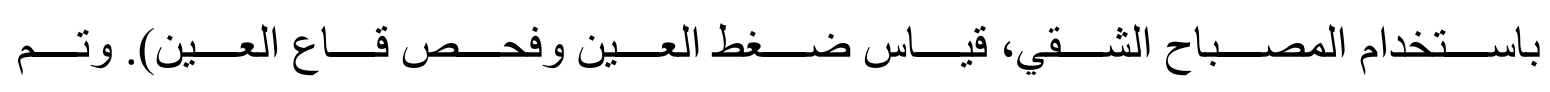
استخدام التصوير المقطعي للبنتاكام للكثيف عن انتشار القرنية المخروطية. 


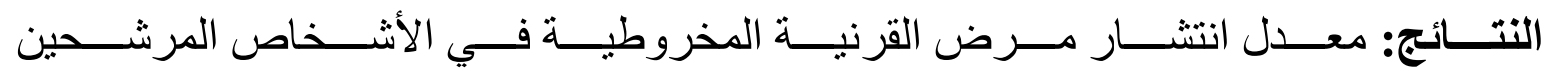

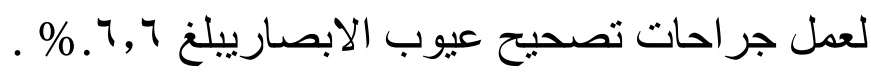

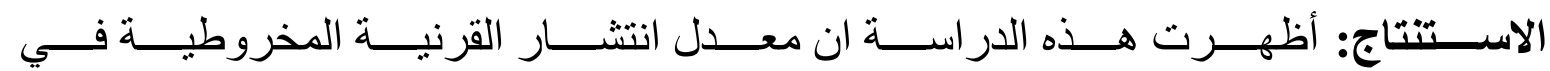

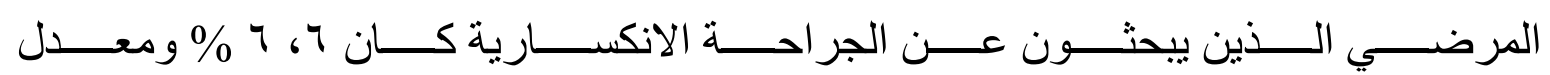

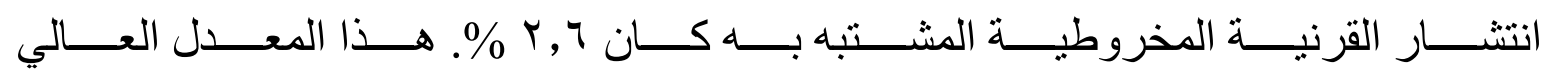

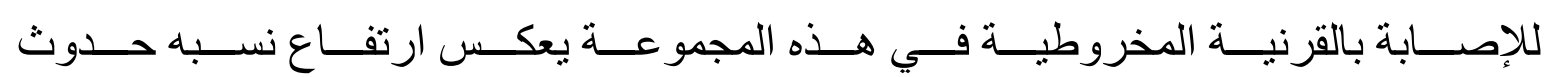

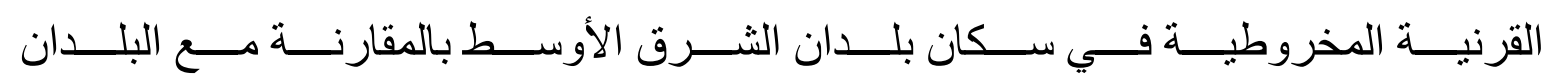
الغربية. 